\title{
Feeling the neurobiological self
}

The self may be defined in terms of responses to experience.

\section{The Feeling of What Happens: Body and Emotion in the Making of Consciousness \\ by Antonio Damasio \\ Harcourt Brace: 1999. 386 pp. \$20, £20}

\section{Raymond J. Dolan}

The American philosopher Susan Langer, one of the most insightful commentators on emotion, proposed in her book Mind: An Essay on Human Feeling (Johns Hopkins University Press, 1988) that the most vexing question in the philosophy of the biological sciences is how something called 'feeling' enters into the physical events that comprise an organism. She suggested that feeling stands "in the midst of that vast biological field which lies between the lowliest organic activities and the rise of mind". Antonio Damasio's stunning book provides us not only with an account of the embodiment of feeling states, but also with a related proposal for understanding two important questions in neuroscience, the nature of self and the nature of consciousness.

From the author's perspective, the problem of consciousness can be described in terms of how the movie in the brain is generated and, more fundamentally, how the brain generates a sense of self that is the very subject of experience. The movie in the brain provides the focus for most current neurobiological work on consciousness; the issue of an experiencing organism is, for the most part, dismissed as currently intractable. Indeed, there is an assumption among neuroscientists that a programme of research focusing on the self runs the risk of ridicule. After all, nobody wants to be accused of resurrecting the homunculus. Yet many of the illnesses that cause the most sustained human suffering, such as schizophrenia, are primarily disorders of selfhood. The astonishing boldness of The Feeling of What Happens is that it unashamedly grapples with these issues, and in the process provides the first truly compelling neurobiological account of the self.

Damasio's principal arguments are founded on a premise that the maintenance of a stable internal milieu is an imperative in regulating the life of any organism. Damasio suggests that the emergence, in evolution, of organized neural systems in the service of this function provides the initial steps towards an emergence of self. In effect, the self has a preconscious biological precedent, the protoself, which corresponds to a coherent collection of neural patterns that map, moment by moment, the physical state of the organism.

The relevant neural structures include

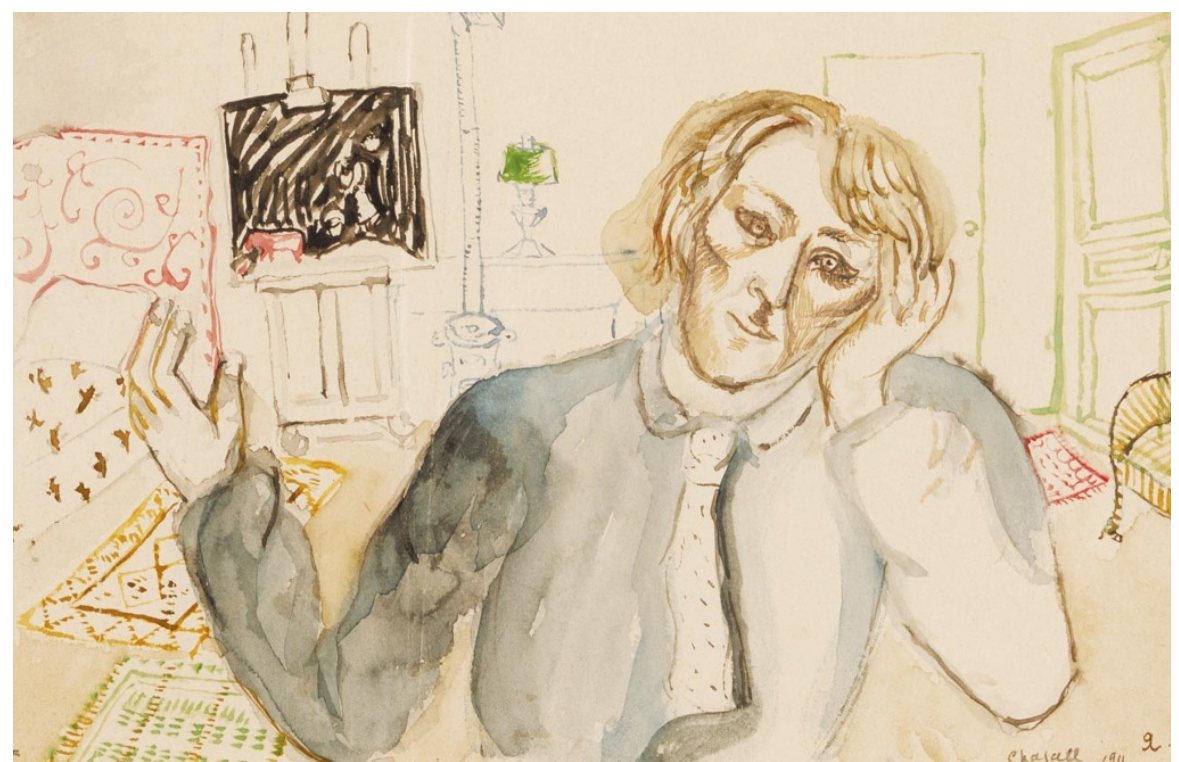

Self-portrait: allowed in Chagall's world, but scientists researching the self risk ridicule. brainstem nuclei, hypothalamus, medial forebrain and insular and somatosensory cortices. This extended system creates a firstorder representation of current body states. In parallel, sensory maps are created that represent objects - whether objects in the world or mental images. Their interaction necessarily alters the current state of the organism. This leads to the central proposition that the basis for a conscious, knowing self is a feeling state that arises when organisms represent a non-conscious proto-self in the process of being modified by objects. In essence, a sense of self depends on the creation of a secondorder mapping, in certain brain regions, of how the proto-self has been altered.

Damasio proposes important conceptual distinctions between core and autobiographical self, between core and extended consciousness and between emotion and feeling. Core self is the transient protagonist of consciousness that is continuously generated through encounters with objects. In contrast, autobiographical self is heavily dependent on the formation of enduring experiential memories, attention and language. Personal identity is an obvious concomitant of an autobiographical self.

Core consciousness is a consequence of the same mechanisms that generate core self, with the added element of enhanced processing of objects that were involved in generating core self. By contrast, extended consciousness depends on holding in mind, over time, a multiplicity of neural patterns that describe the autobiographical self. An important element here is that these patterns themselves constitute objects capable of generating core consciousness. What necessarily follows is a functional interdependency between, on the one hand, core self and core consciousness and, on the other, autobiographical self and extended consciousness.

This neurobiological account of core self has an interesting parallel in recent philosophical debates about the nature of self. The philosopher Galen Strawson has proposed that the self could be defined as a subject of experience that is a single mental thing. His introspectively derived account corresponds remarkably closely to Damasio's core-self concept in that both postulate an evanescent self, devoid of identity, which comes into being in response to unique experiences. In Damasio's account, core self presents to the organism a fleeting sense of subjectivity to which knowledge of the moment can be attributed.

Core self and core consciousness have their origins in a mapping of body states and are about two facts, the organism relating to objects and the fact that this relation causes a change in the organism. It follows that a central agenda for a neurobiology of consciousness involves a description of how, in turn, the brain maps the organism and objects, and, most importantly, the dynamics of their relationship.

One of the most important implications of Damasio's thesis is surely that consciousness is not the privileged domain of any sensory system. This is already borne out by observations that acquired damage within a sensory channel does not impinge upon core 
consciousness (a possible exception may be the special case of the somatosensory system). Nevertheless, this proposal is likely to be highly controversial in that it casts doubt on any research that seeks to provide a comprehensive account of consciousness from the perspective of a single sensory modality such as vision. Paradoxically, for those of us who study emotion, it is gratifying to think that, without the usual fanfare, we have implicitlybeen studying consciousness.

At the end of his life, the British poet W. H. Auden movingly acknowledged an indivisibility of self and bodily experience in referring to his body as "my tutor also, but for whose neural instructions I could never acknowledge what is or imagine what is not". To think, imagine and feel are the very stuff of mind and in Damasio's account they are deeply rooted in a sense of body. The exposition of this relatedness in The Feeling of What Happens constitutes a remarkable work of intellectual daring. The challenge posed is a radical redefinition of what constitutes the central concerns for a comprehensive account of consciousness. Indeed, by placing human emotion and feeling at centre stage, Damasio ensures their rehabilitation into mainstream neuroscience, a move first initiated in his previous book, Descartes' Error (Putnam, 1994). Any of the above achievements would make this book recommended reading; combined, it becomes compulsive and compulsory.

Raymond J. Dolan is in the Wellcome Department of Cognitive Neurology, University College London, Queen Square, London WC1N 3BG, UK.

\section{The claim of the inner world}

\section{Cassandra's Daughter: A History of Psychoanalysis \\ by Joseph Schwartz \\ Penguin: 1999. 339 pp. £20, \$20.95}

\section{Jane Kitto}

It is a brave man who attempts a history of psychoanalysis in 300 pages. The controversies are legendary, and most people already have an opinion and know something about the personalities involved. We need a history of psychoanalysis for the general reader, but I am afraid this is not it, even though it goes some of the way.

Joseph Schwartz brings Sigmund Freud to life: his early scientific struggles; his search for somewhere to make his mark; his early theories; and the collaboration with Josef Breuer which came unstuck. He deals with Freud's journey towards a workable method, the 'analytic hour'. There is a long section on the vexed matter of the seduction theory and child sexual abuse. Schwartz leaves Freud the theoretician at about 1910 (and about one- third of the way through the book); the next two chapters describe the early splits with Alfred Adler and Carl Jung.

He then shifts to the United States with a fairly brief account of psychoanalysis there and a long and interesting discussion of the reforms in psychiatric institutions during the early decades of the century, specifically the work of William Alanson White and Harry Stack Sullivan. Most of the last third of the book deals with developments in Britain, beginning with Melanie Klein and child analysis, followed by a brief discussion of Jacques Lacan in France.

This is no potted history. Schwartz began as a physicist, and has become a practising psychotherapist via research into mental health. He is a staunch defender of psychoanalysis, and he handles the question of its scientific status, or otherwise, robustly. It is, he says, "a science in the sense that it attempts to understand human subjectivity in material terms". In the final chapter he takes up the question of neuroscience and psychopharmacology, arguing that although drugs have their place in treatment, they do not replace psychoanalysis; "in the absence of a deeper understanding of mind-body connections, such pharmacological agents will always have a certain hit or miss quality to them". Neither pharmacology nor psychoanalysis has a magic bullet. Schwartz believes that psychoanalysis is a serious business, and has no truck with dinner-table chatter. The psychoanalytic profession, not having been very good at defending itself, needs this kind of support.

As a scientist, Schwartz has his feet firmly on the ground. But there is another Schwartz who gives the impression of trying to ride two or more horses at once. The book is partial in both senses of the word. While there is no harm in this, provided it is made explicit, Schwartz's preferences are left to the reader to discern - although this is not too difficult. It is not until page 138 that he shows his hand: "This book could be said to be trying to position psychoanalysis as an extension of the Western scientific tradition as a way of understanding the human inner world". But it is sub-titled A History of Psychoanalysis, and the result is an uncertainty of focus which leads one to wonder why he has chosen particular topics to expand on.

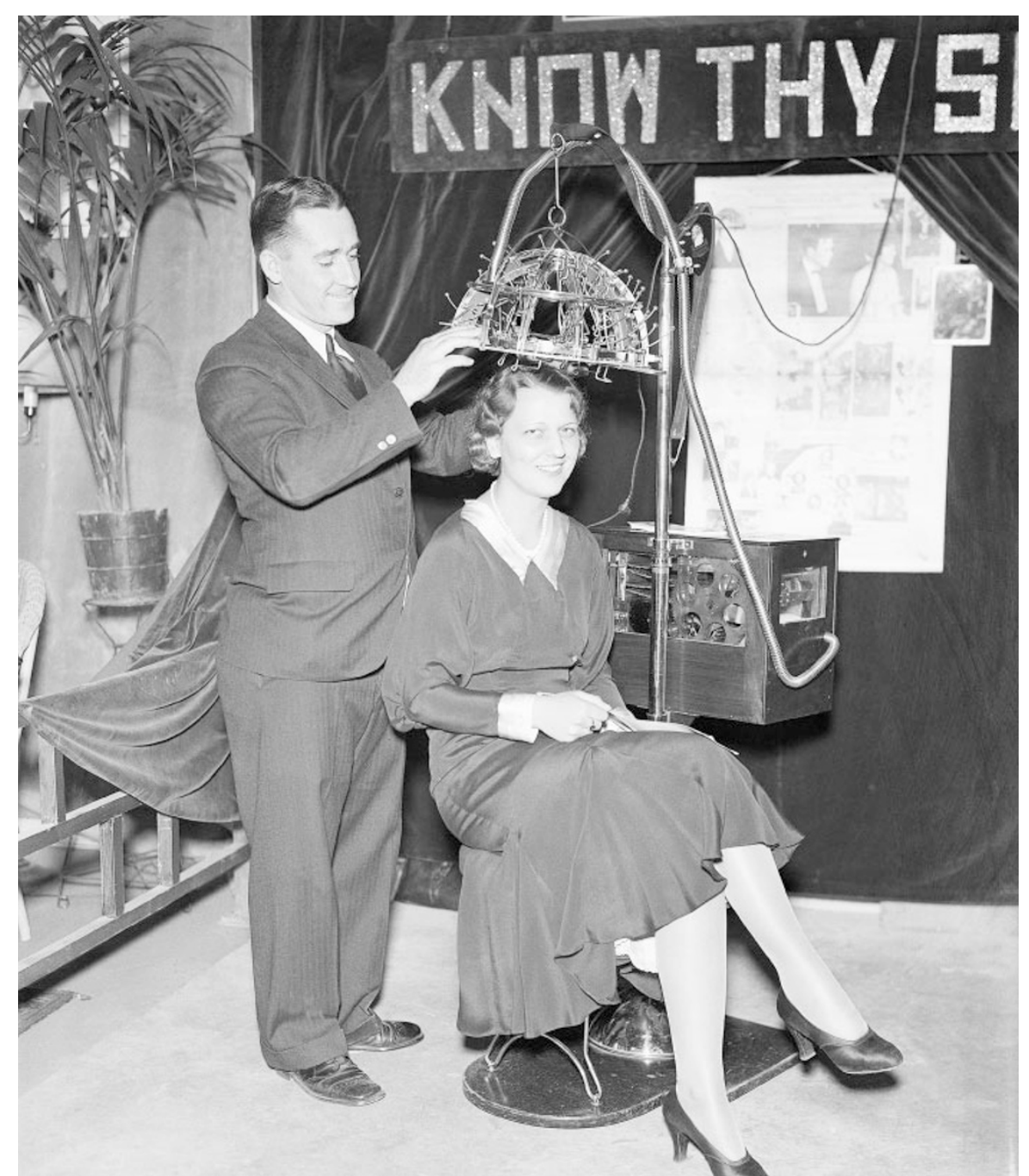

Capitalizing on psychoanalysis: a psychoanalysing machine exhibited at an industrial show in 1931. 